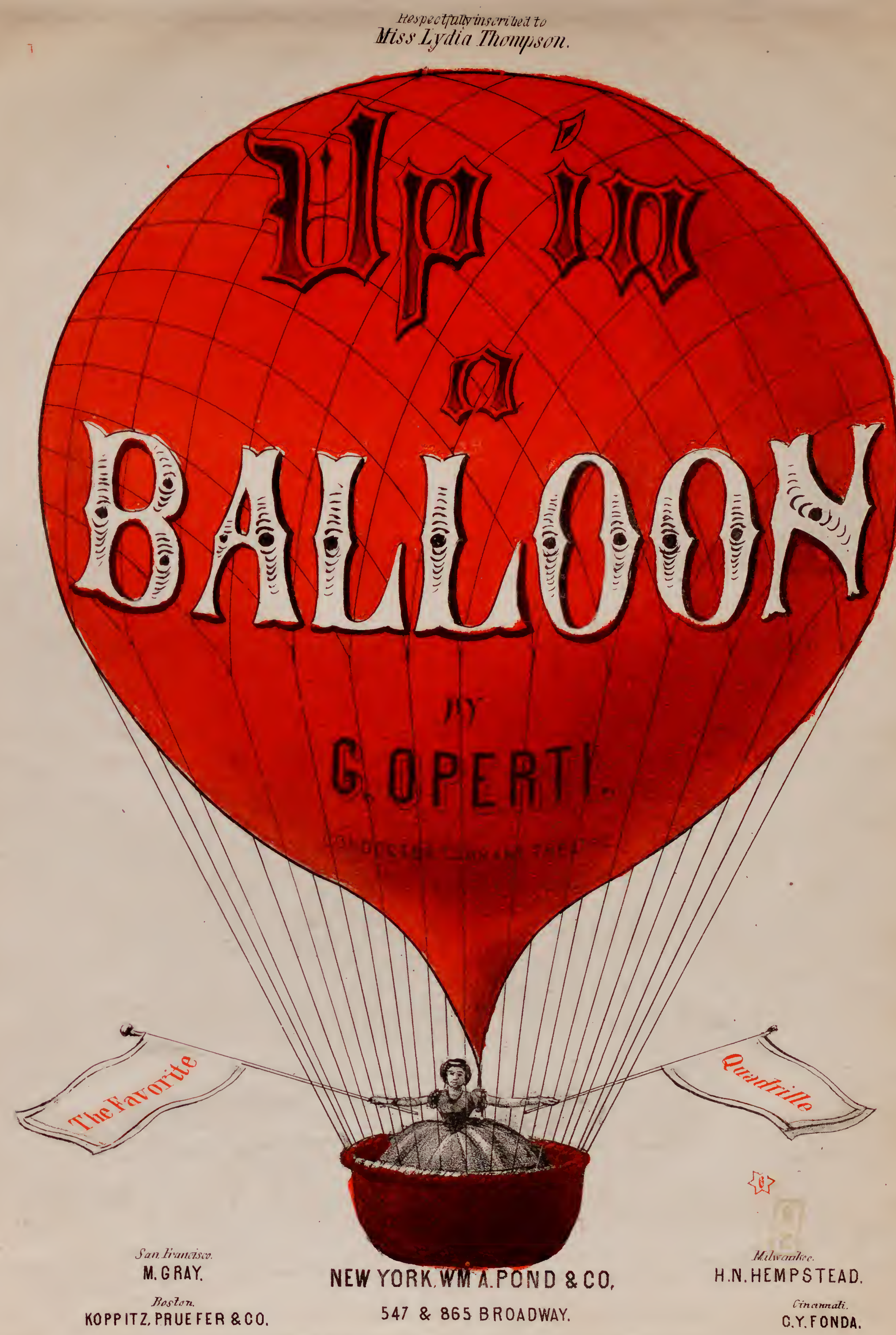




\section{UP IN A BALLOON .}

\section{QUA DRILLE.}

Inscribed by permission to

QUADRILLE.

Easy edition.
Miss LY DIA THOMPSON.
G. OPERTI

Piamist to His Mujesty

Victor Emmanuel II. Fing of Italy
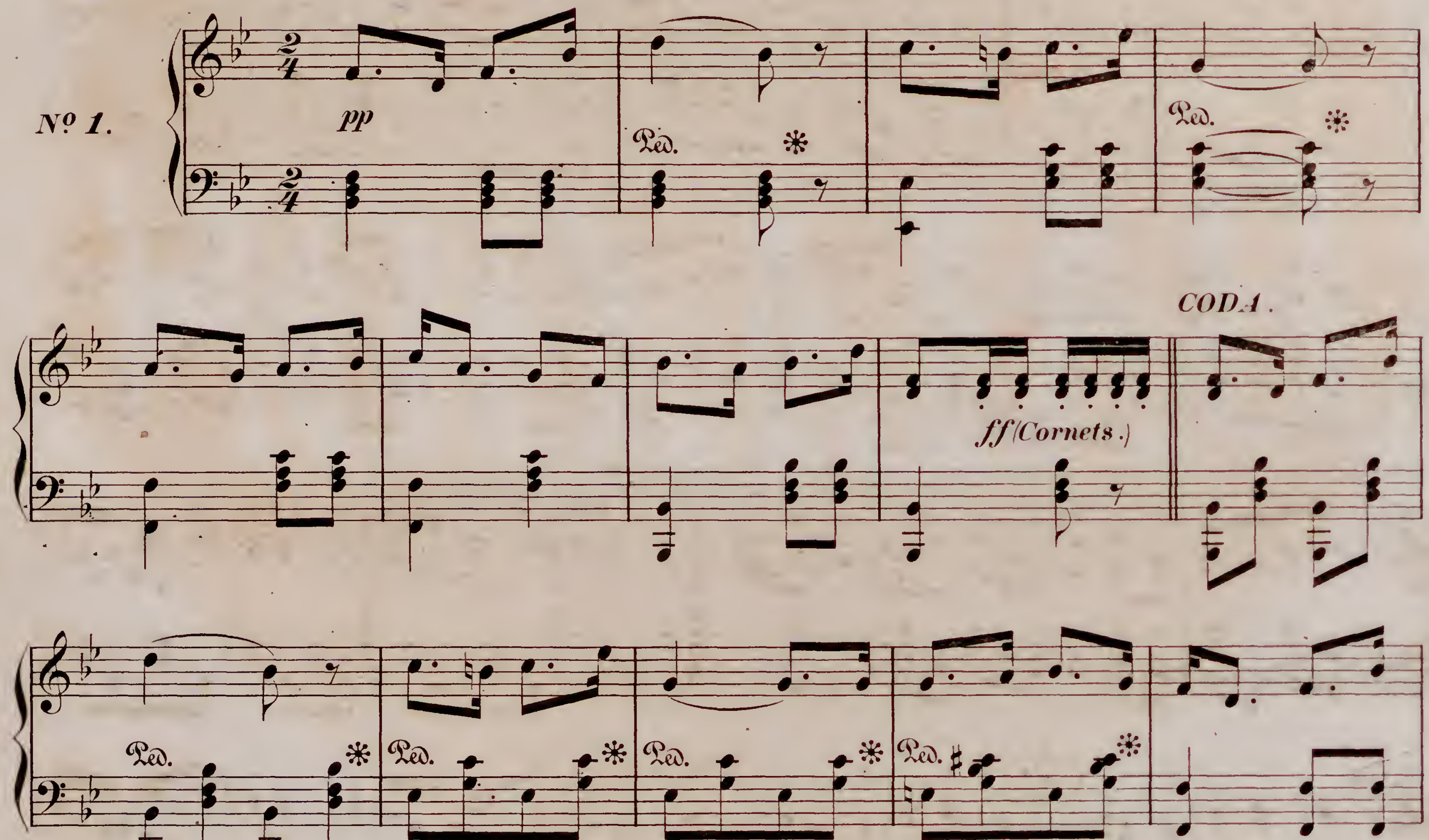
立.
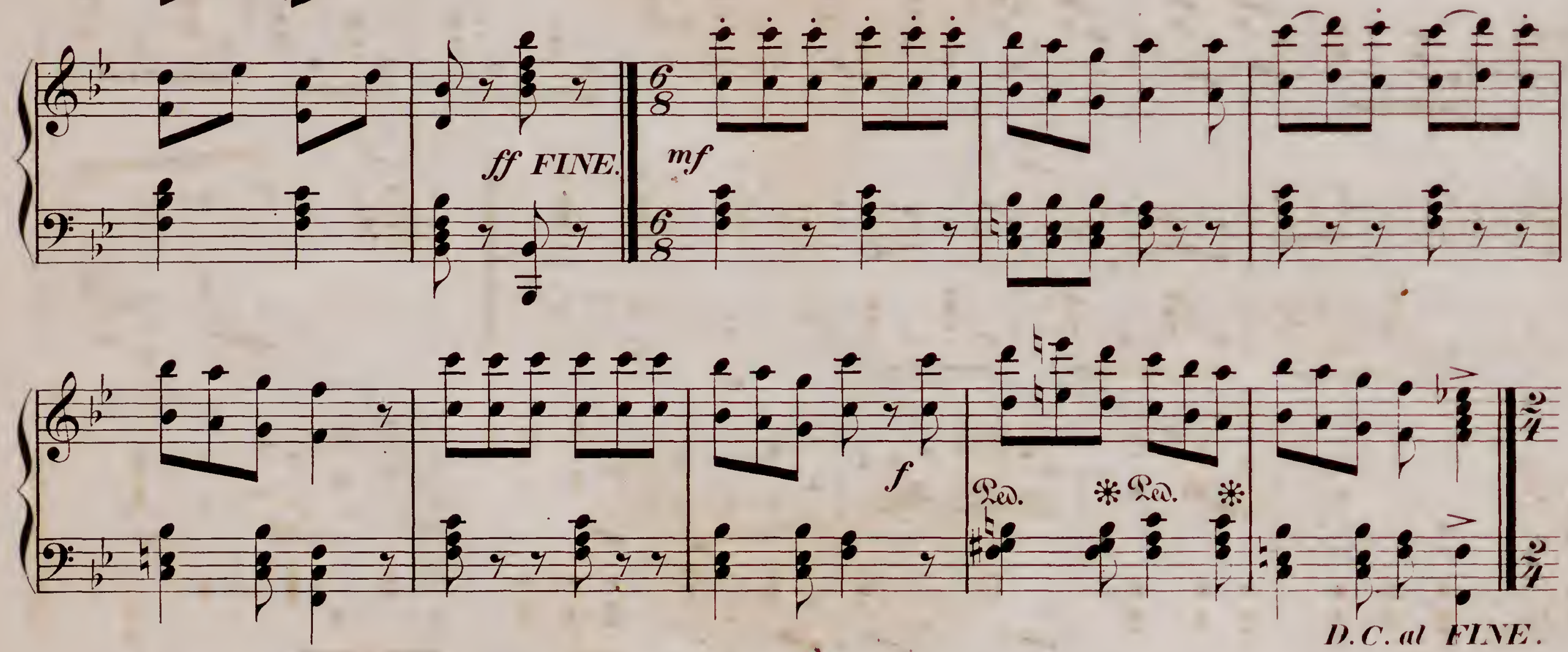

By the same Composer "RACKETTY JACK QLADRILLE" and SONG

Ent. ace. to Aet of Congress, A.D.1869, by Wm.A.Pond and Co. in the Clerk's Off. of the Dt.Ct. for the Southern Dt. of N. Y . 
"PAL O' MINE

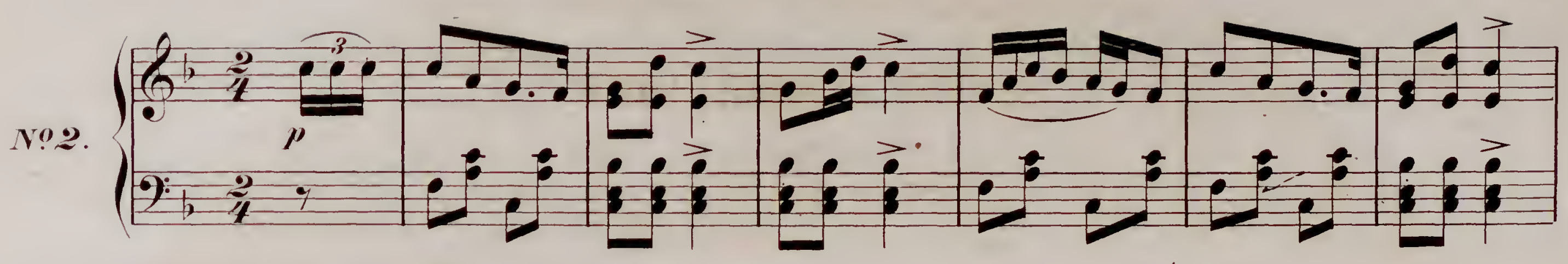

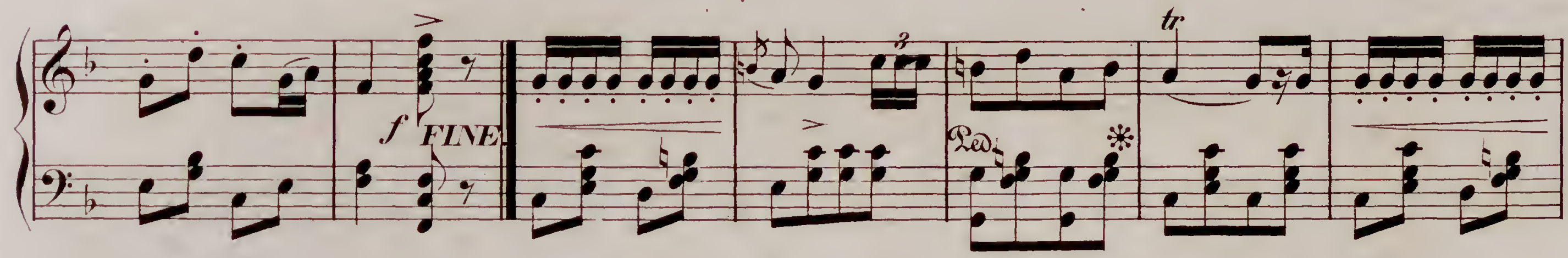

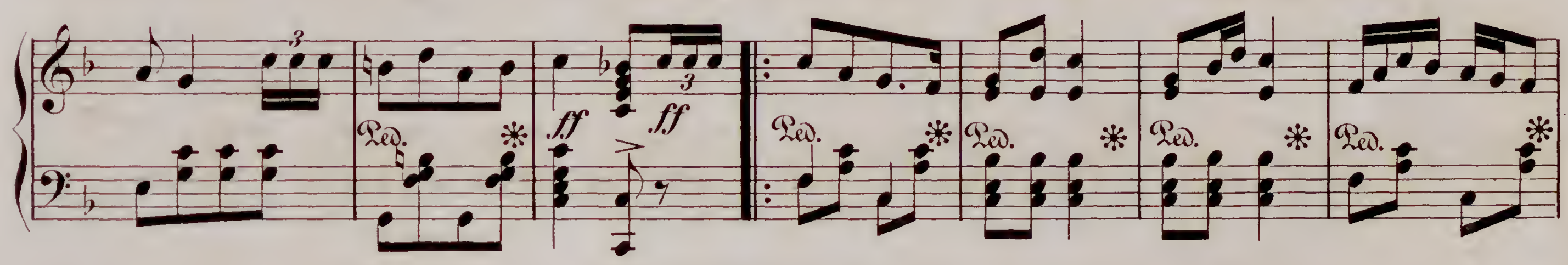

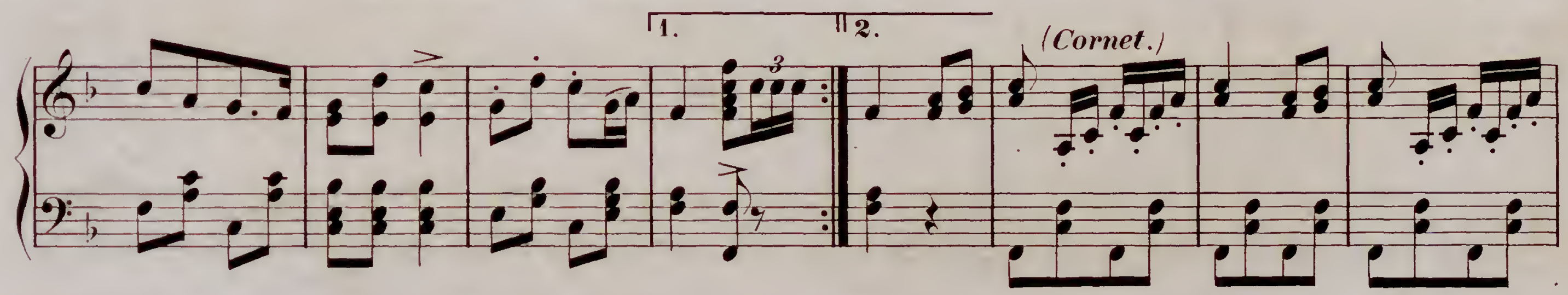
(6.

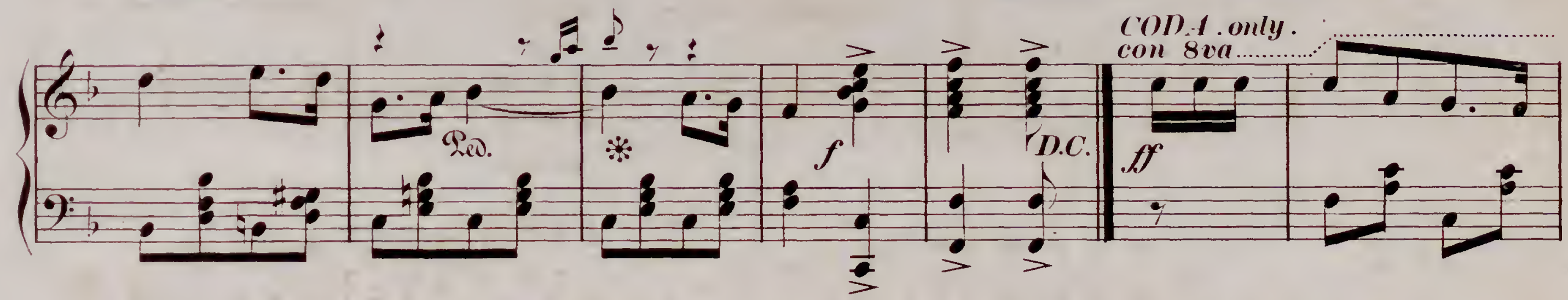

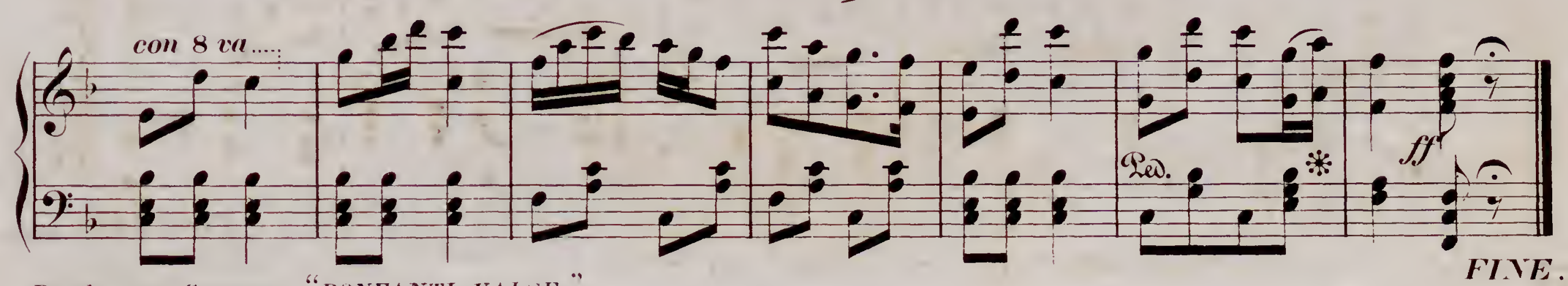
By the same Composer "BONFAYTI VALAE"

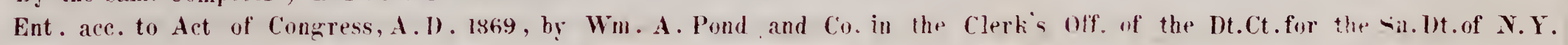


4

\section{"THE BELL GOLS A HIVGIVG FUR S.HAH}

No.3.

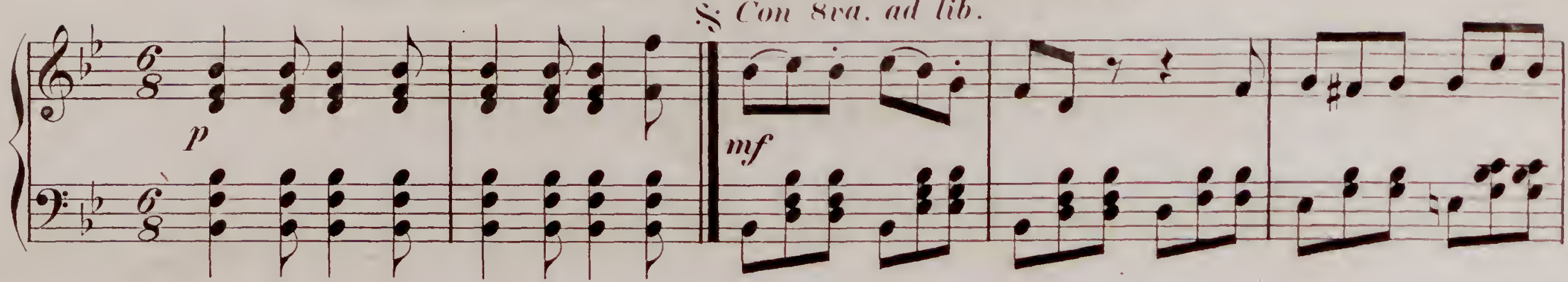

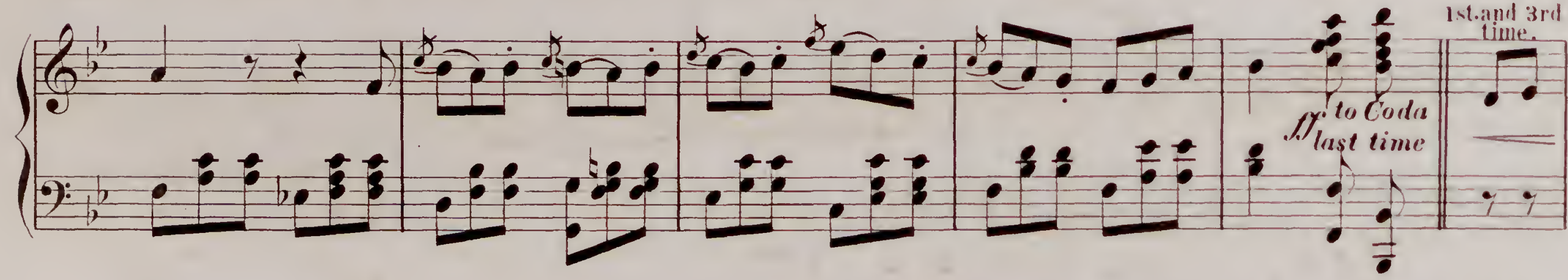

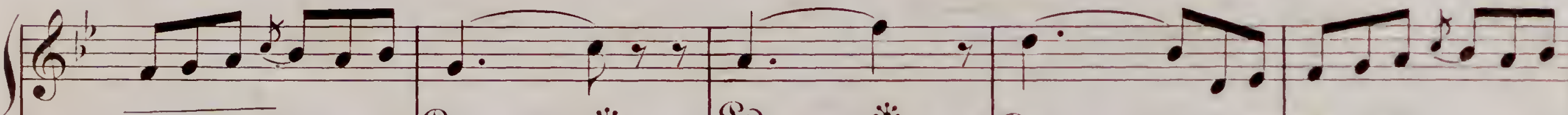

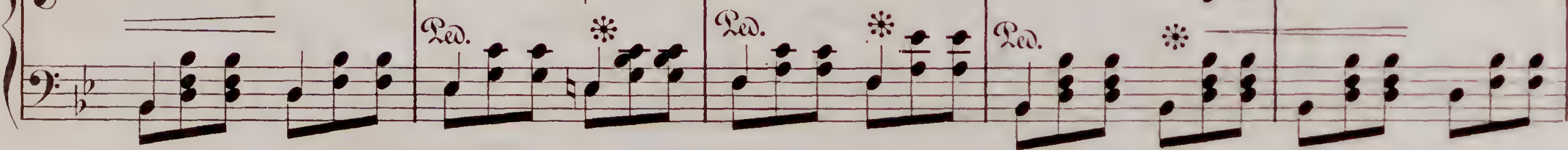

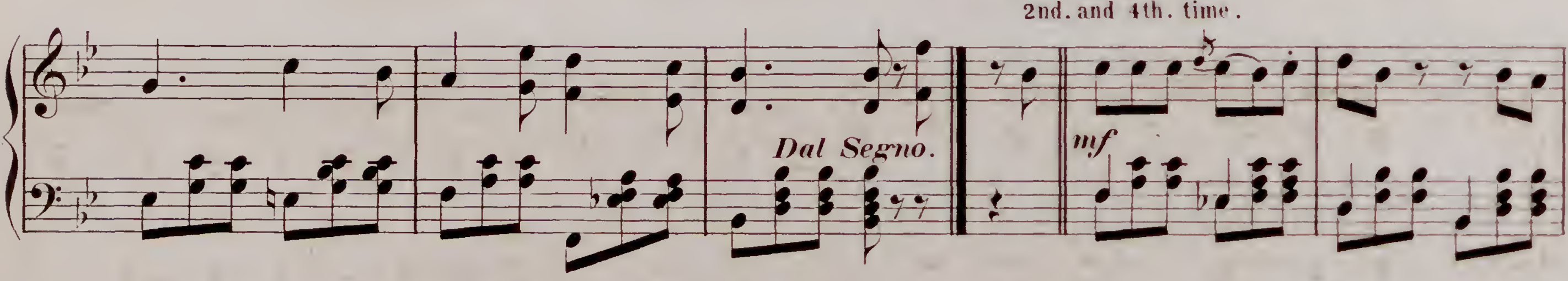

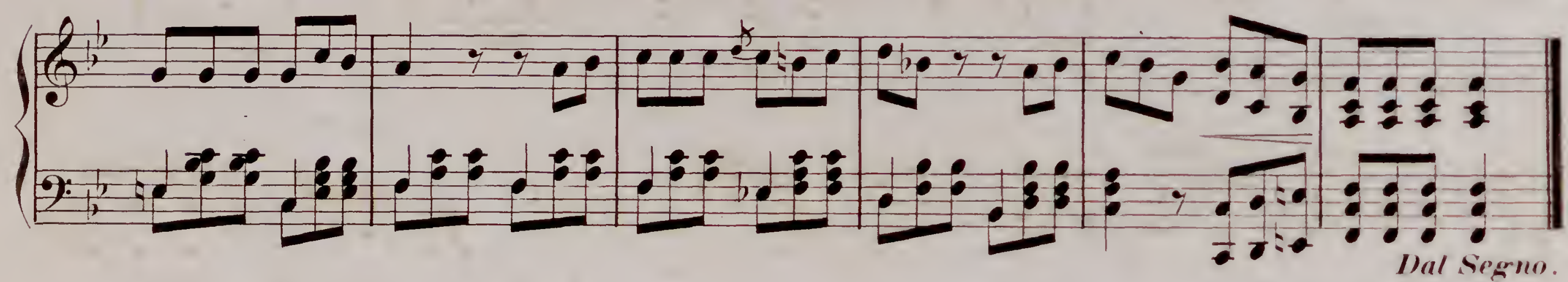
CODA only.
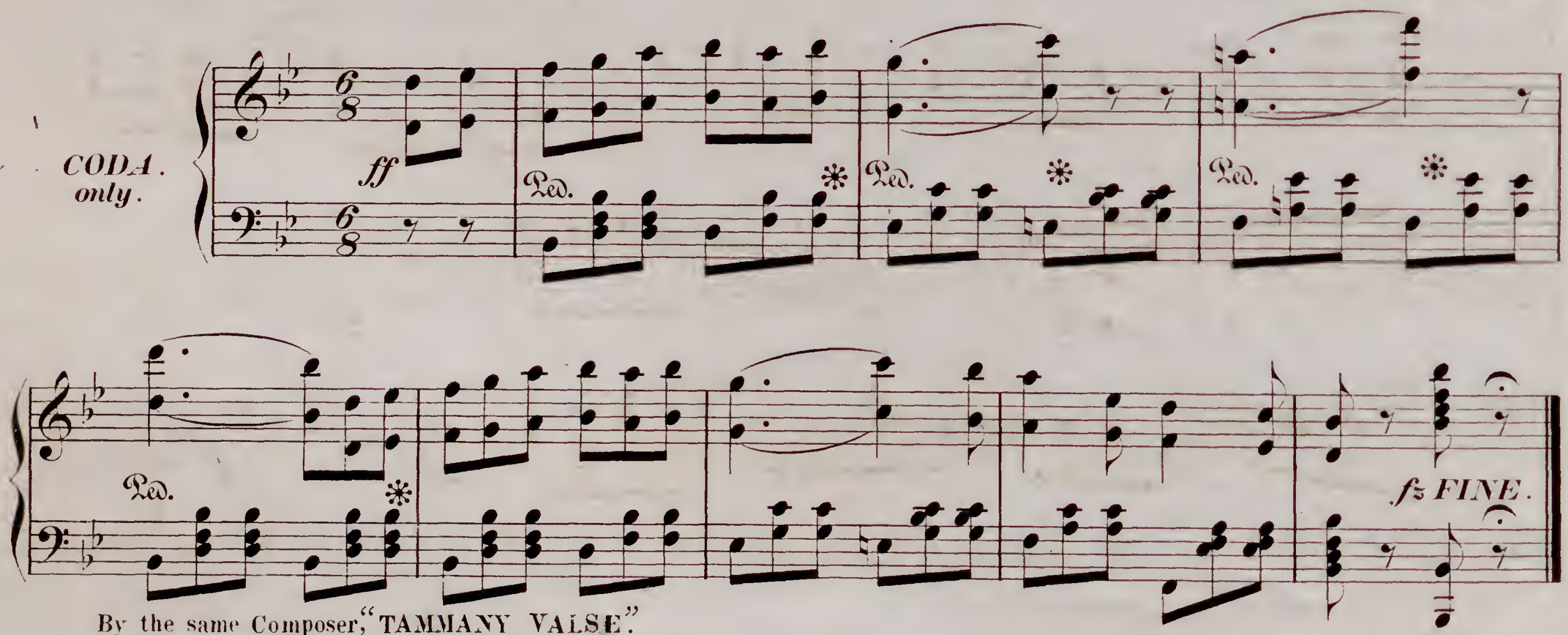

By the same Composer" TAYHAYY YAISE"

Eint. ace.to Act of Congress, A.D.1869, by Wm.A. Pond and Co. in the Clertis off. of the Dt.Ct. for the Sn.Dt.of N.Y. 
UAID.OF THE MILL.
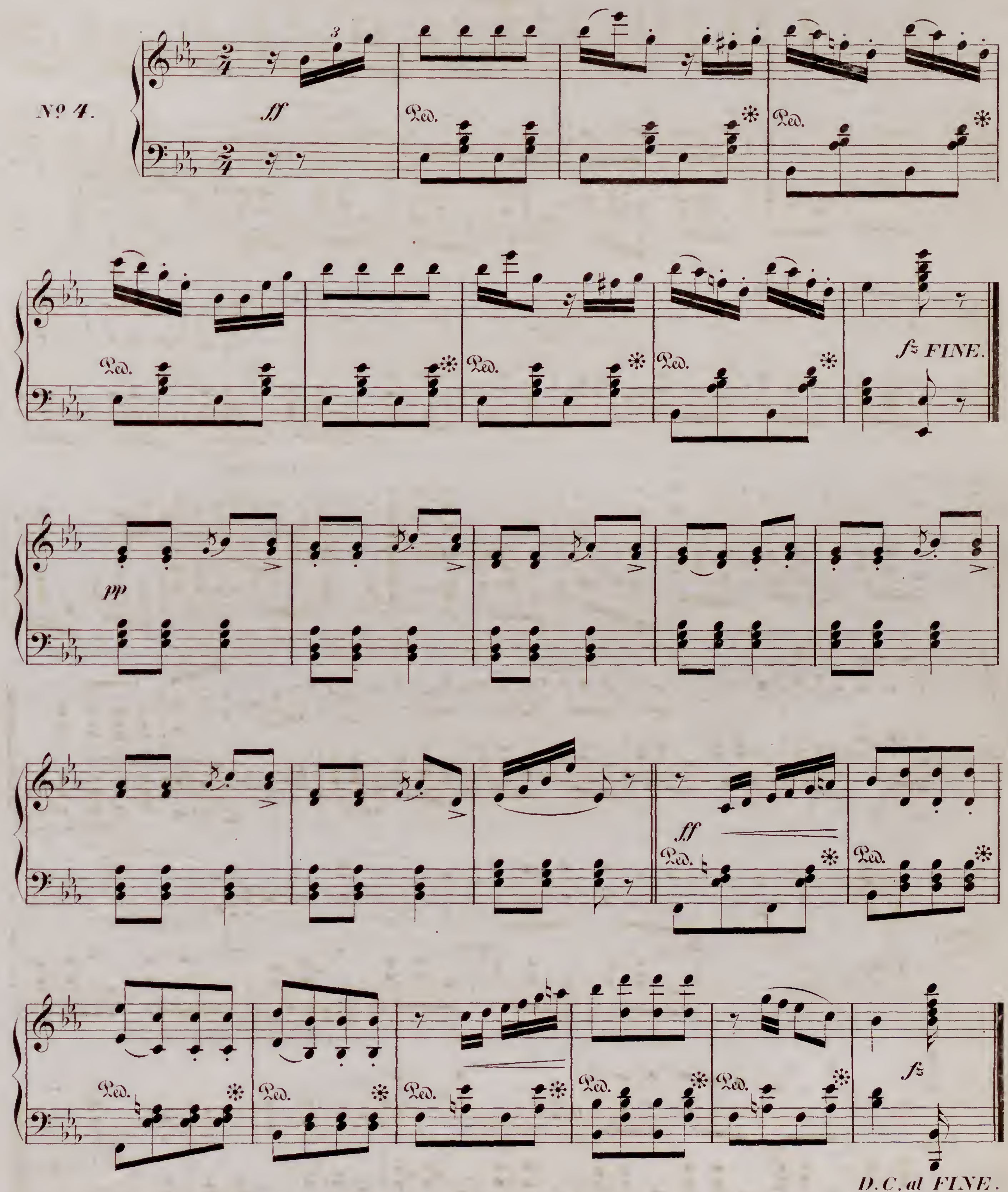

By the same Composere, somebody's barline."

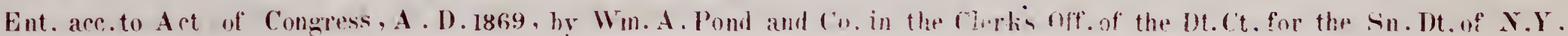


6

"TAPPING AT THE GARDEN GATE" and"HAMLET SMILING IN THE VALE."

N? 5

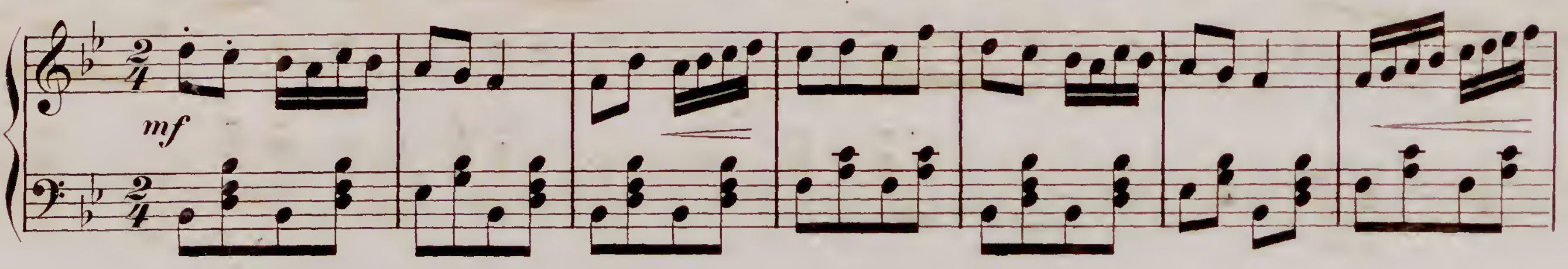

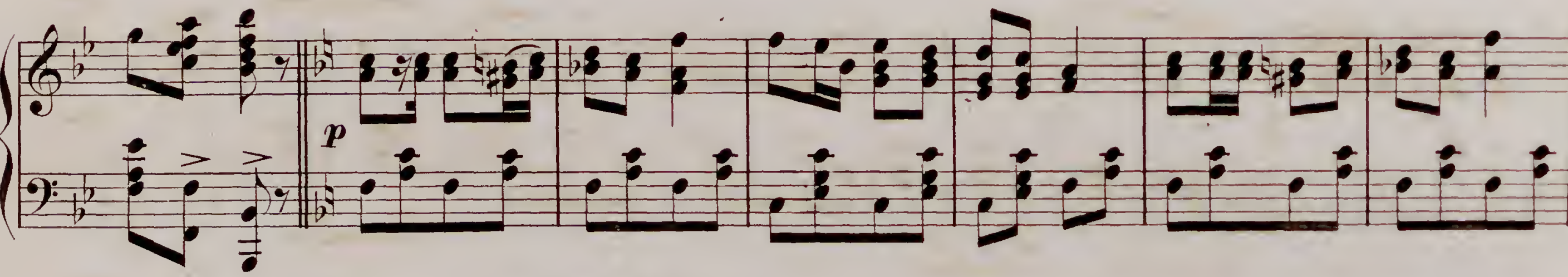

( and. Time.)

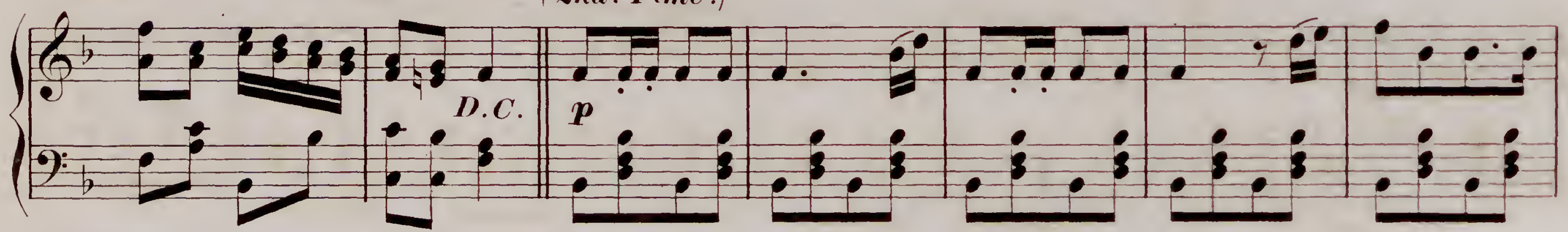
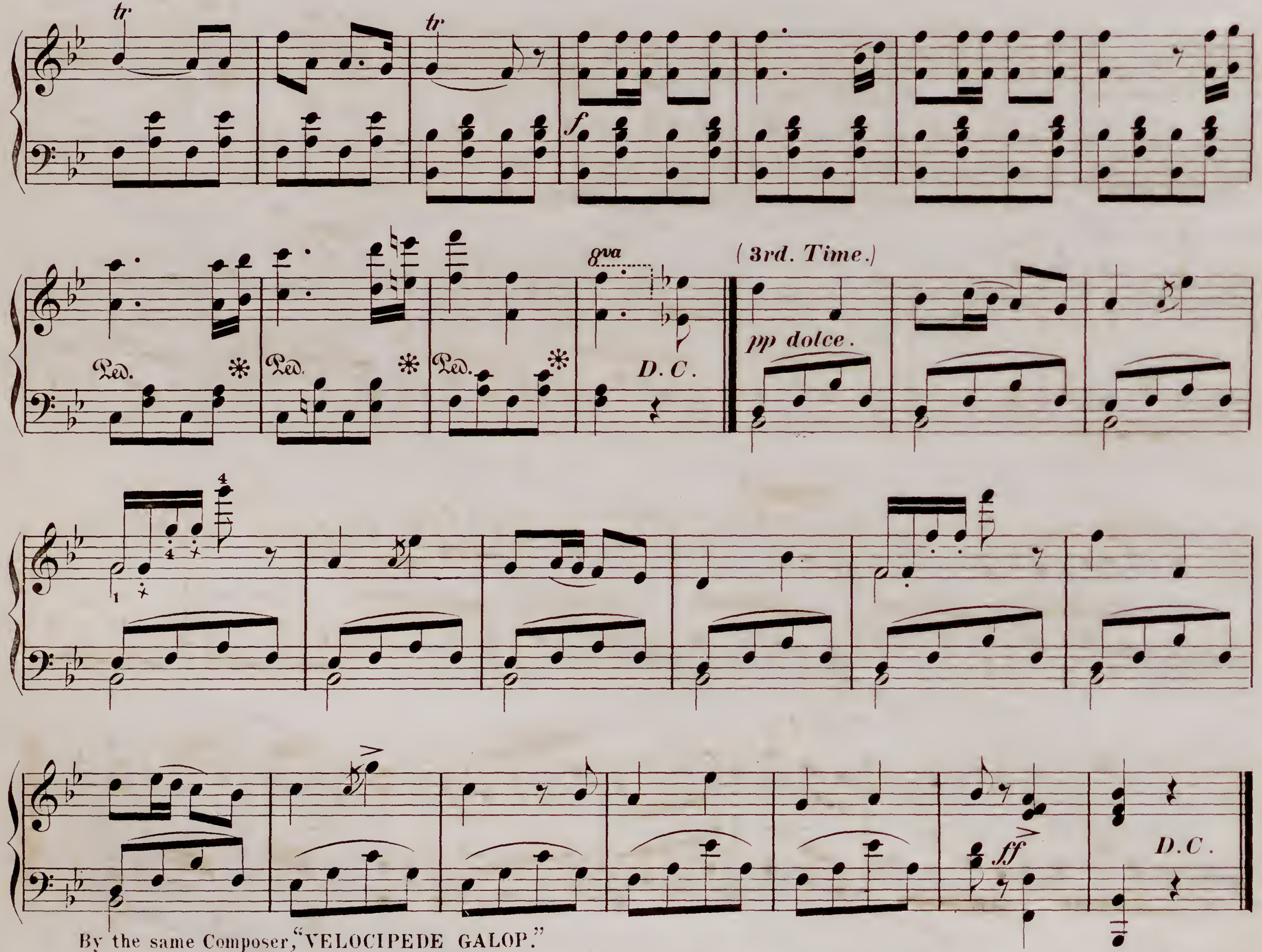

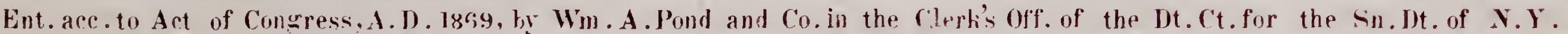


(4th.Time.)

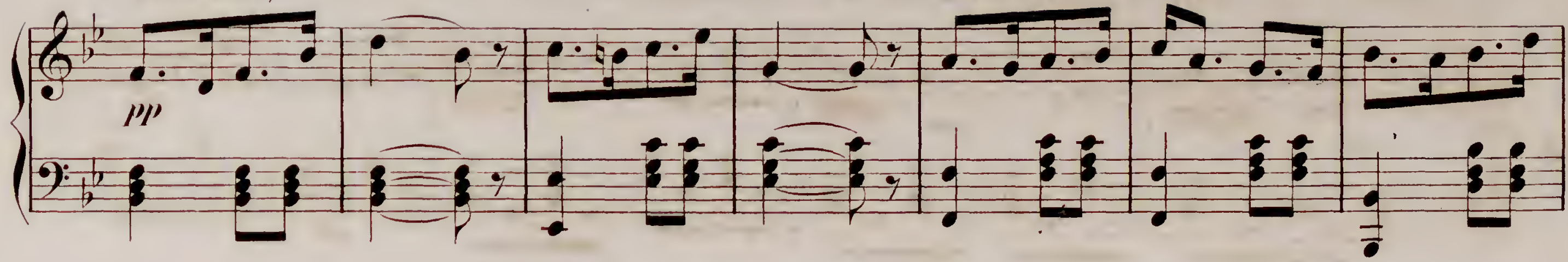

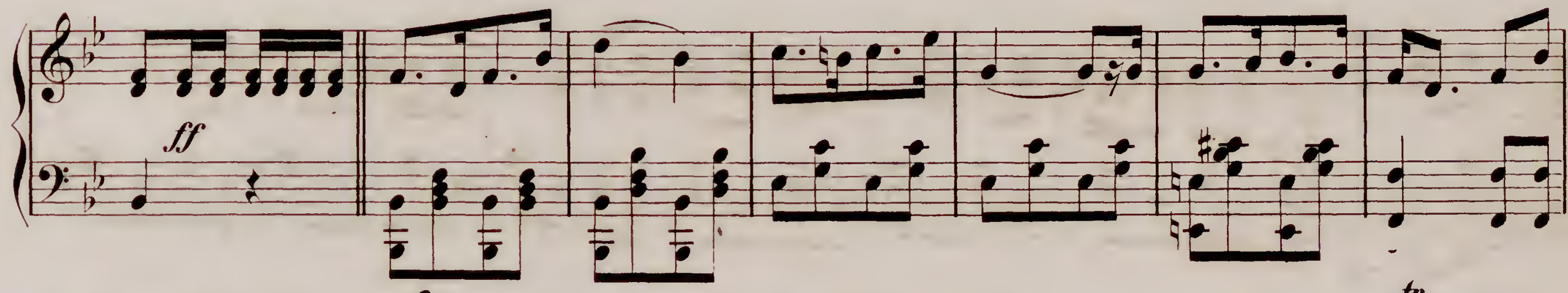

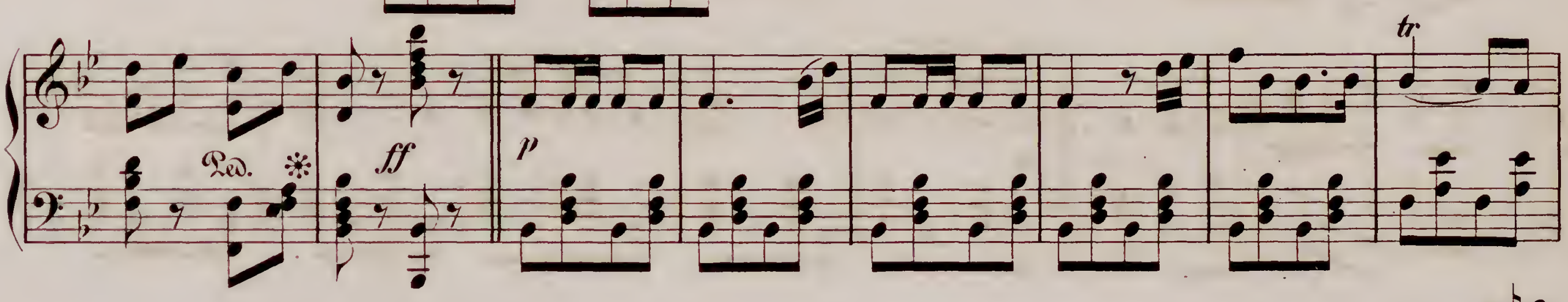

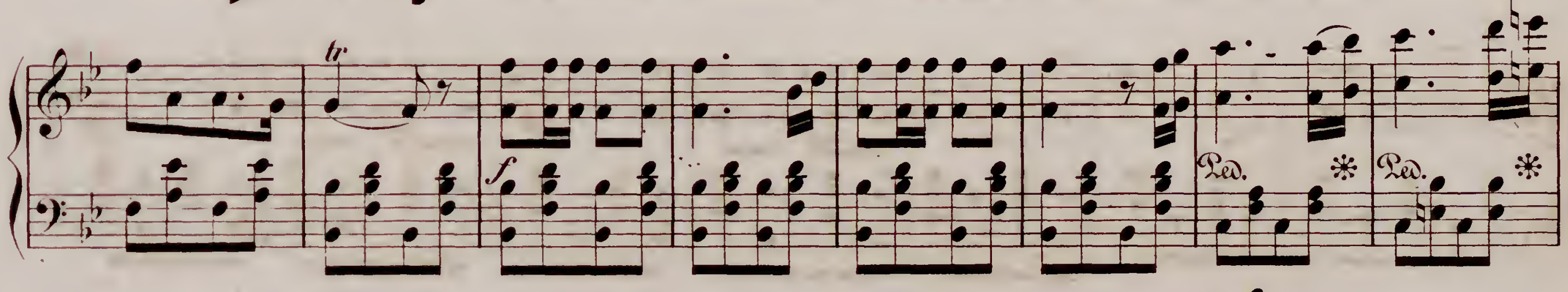

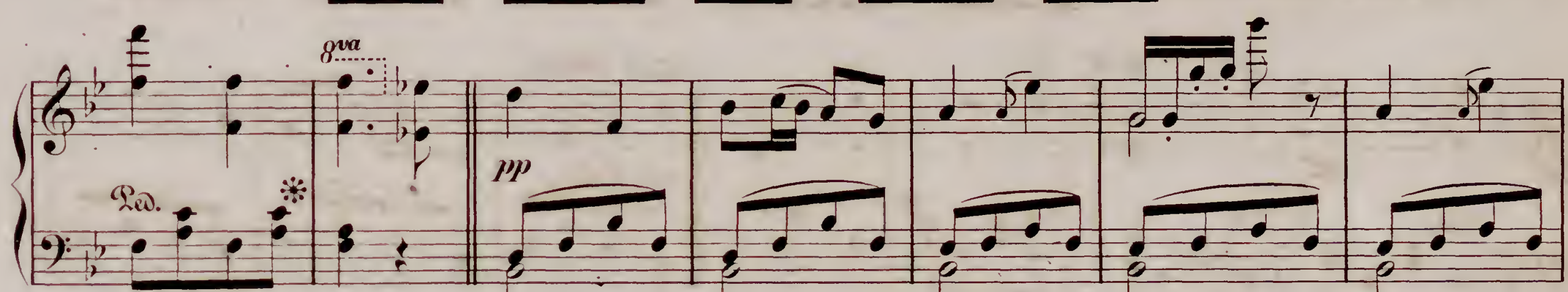
$\because \cdots \div \div \div \cdots \cdots$ coms

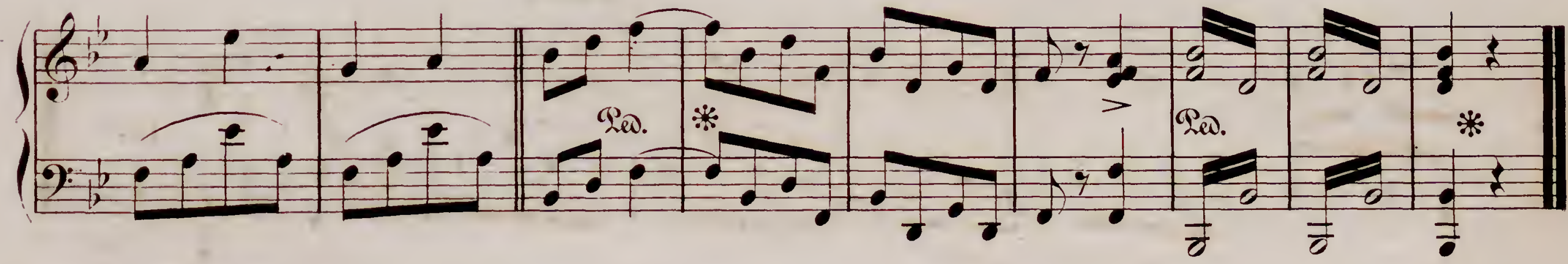


